\title{
A case of leptospirosis in a child with unusual clinical manifestation
}

\author{
A. Biswas ${ }^{1}$, R. Kumar' ${ }^{2}$ A. Chaterjee ${ }^{3}$, A. Pan $^{4}$ \\ ${ }^{1}$ RMO Cum Clinical Tutor, Department of Pediatrics, IPGME \& R and SSKM Hospital, West Bengal, \\ India, ${ }^{2,3}$ Registrar Department of Pediatrics, AMRI hospital, Kolkata, West Bengal, India, ${ }^{4}$ Lecturer, \\ Department of Paediatrics, College of Medical Sciences, Bharatpur, Nepal
}

\begin{abstract}
Leptospirosis is a re-emerging zoonotic disease with a worldwide distribution. In the mild form it may present as flu like illness. Severe form characterized by jaundice, renal dysfunction and hemorrhagic diathesis is referred to as Weil's syndrome. Very few cases have been reported in India, and pediatric cases are extremely rare. We report a case of leptospirosis in a 12 year old girl who presented with irregular fever, malaise and spontaneous bleeding from nose. She also had headache, vomiting, subconjunctival hemorrhage, photophobia, pain abdomen, cervical lymphadenopathy, myalgia, and arthralgia. She developed severe coagulopathy, bilateral pleural effusion, ascitis, acalculous cholecystitis ultimately leading to ARDS and later multi-organ failure. ELISA for IgM leptospira was sent which came to be positive. She was given several units of packed cell, platelet concentrate, and plasma transfusion, and later mechanical ventilation and inotropic support. The patient was put on intravenous penicillin $\mathrm{G}$. which was continued for 10 days. Three weeks following admission, she had made a complete recovery and was discharged.
\end{abstract}

Key words : leptospirosis, severe coagulopathy, acute respiratory distress syndrome (ARDS).

\section{Introduction}

Leptospirosis is a zooanthroponosis caused by a pathogenic spirochete of genus Leptospira, the species Leptospira interrogans. ${ }^{1}$ It is characterized by a broad spectrum of clinical manifestations varying from inapparent infection to fulminant fatal disease. In the mild form it may present as flu like illness with headache and myalgia. Severe form characterized by jaundice, renal dysfunction and hemorrhagic diathesis is referred to as Weil's syndrome. ${ }^{1}$ The first case of leptospirosis

Correspondence: A. Pan

E-mail: atanu8k@yahoo.co.uk from India was reported in 1929 by Taylor and Goyal from Andaman and Nicobar Islands. ${ }^{2}$ It is known to occur in sporadic as well as epidemic form in mainland India. There has been a significant increase in the reported cases of leptospirosis from India since 1980s. Epidemics have been increasingly reported from Orissa, Maharashtra, Karnataka, Tamil Nadu and Kerala. ${ }^{3,4}$ The primary lesion caused by leptospires is damage to the endothelial lining of small blood vessels with resultant ischemic damage to liver, kidneys, 
Journal of College of Medical Sciences-Nepal, 2012, Vol-8, No-2

meninges and muscles. Alow index of suspicion of this disease coupled with the diversity and non-specificity of the presentation accounts for the significant number of cases that go unrecognized. ${ }^{5}$ Leptospirosis is a grossly underdiagnosed disease in our country due to lack of awareness, protean manifestations and inadequate diagnostic facilities in many areas. Early diagnosis and appropriate treatment can prevent fatal outcome. $^{6}$

\section{Case report}

A 12-year-old girl was admitted to the medical college and Hospital, Kolkata in August 2004 with a history of irregular fever and malaise for last 11 days and spontaneous bleeding from nose. On admission, she had fever, headache, vomiting, sub-conjunctival hemorrhage, photophobia, pain abdomen, cervical lymphadenopathy, myalgia, and arthralgia.

Assessment on admission revealed that she lived in a slum area of Kolkata. She used to take bath with well water. She had not walked barefoot. No other family members became ill in the recent past. There was also history of flood in the local area one month back.

Empiric treatment with intravenous fluid, antipyretic and third-generation cephalosporin was started. Anterior nasal pack was given to arrest the nasal bleed. Initial laboratory evaluation showed severe pallor haemoglobin 4gm\%, total leukocyte count $11000 / \mathrm{mm}^{3}$, $\mathrm{N}^{71} \mathrm{~L}^{28} \mathrm{E}^{1}$, erythrocyte sedimentation rate $70 \mathrm{in} 1^{\text {st }} \mathrm{hr}$, grossly reduced platelet $10000 / \mathrm{mm}^{3}$, Activated Partial Thromboplastin Time 80sec(control 30sec), Prothrombin time 25sec(control 13sec), total serum bilirubin 3mg/dl, unconjugated serum bilirubin $2 \mathrm{mg} / \mathrm{dl}$, aspartate aminotransferase 180, alanine aminotransferase 170 , total serum protein $5 \mathrm{gm} / \mathrm{dl}$ Albumin:Globulin ratio 1.2: 1, alkaline phosphatase $320 \mathrm{IU}$, serum urea $22 \mathrm{gm} / \mathrm{dl}$, serum creatinine $0.7 \mathrm{gm} /$ $\mathrm{dl}$, serum sodium $132 \mathrm{meq} / \mathrm{l}$, potassium $4 \mathrm{meq} / \mathrm{l}$. Widal test, blood for malarial parasite and malarial antigen was non reactive. Blood culture was sent before starting antibiotics.

She was given several units of packed cell, platelet concentrate, and plasma transfusion. There was no effect on severity of bleeding which became more pronounced with the appearance of hemoptysis, hematemesis, melena, and hematuria in the next 3-4 days. Further investigation showed negative serum viral markers for dengue and chikungunya. Skiagram of chest revealed bilateral perihilar fluffy opacity along with bilateral pleural effusion as shown in Fig.1

\section{Figure.1: Bilateral Pleural Effusion}

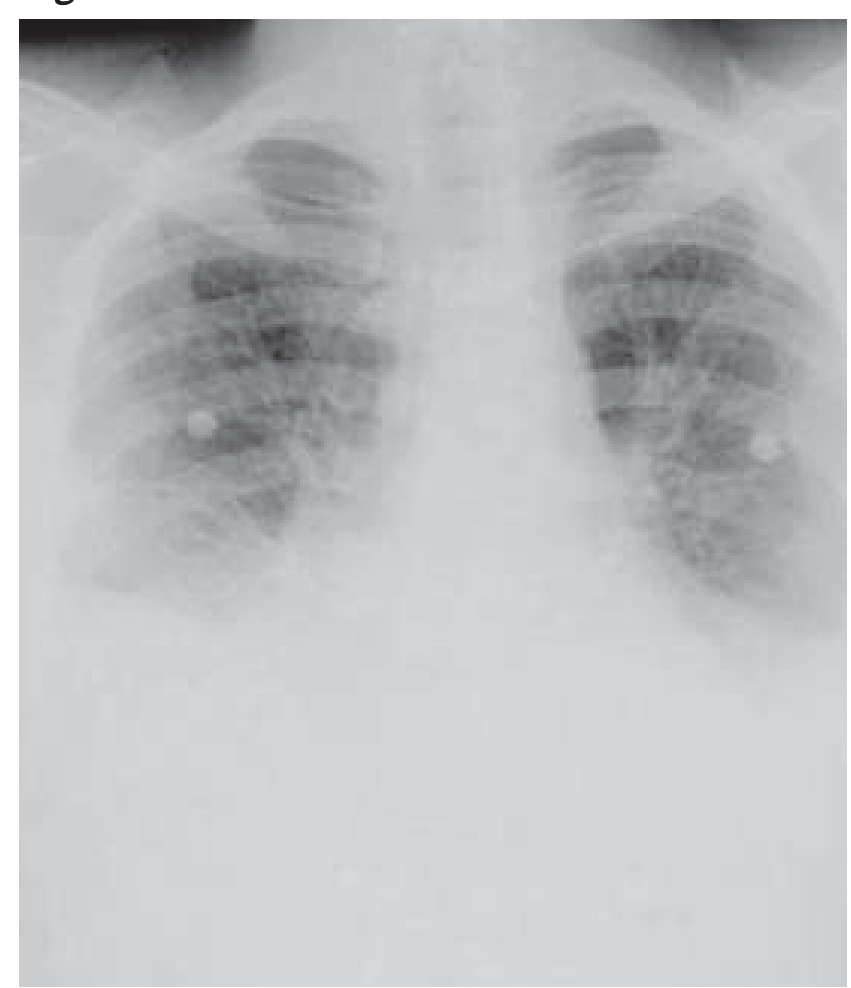




\section{A. Biswas et al. A case of leptospirosis in a child with unusual clinical manifestation}

Abdominal sonography showed ascitis, acalculous cholecystitis mild hepatomegaly and bilateral pleural effusion. Her condition rapidly deteriorated after 5 days as she developed severe respiratory distress, hypotension, and circulatory collapse.

Thus ARDS with multiorgan failure was diagnosed which necessitated patient transfer to ICU. Her laboratory parameters also supported our diagnosis as shown in table 1. Mechanical ventilation, inotropic support and other supportive management was started. Blood culture was negative. We made a provisional diagnosis of leptospirosis and ELISA for IgM leptospira was sent which was positive. The patient was put on intravenous penicillin G. Antibiotics were continued for 10 days. Three weeks following admission, she made a complete recovery and was discharged.

\section{Discussion}

Leptospirosis is a re-emerging zoonotic disease with a worldwide distribution. It was first described in the early $18^{\text {th }}$ century by Adolf Weil and his colleagues. ${ }^{7}$ Very few cases have been reported in India, and pediatric cases are extremely rare. Leptospirosis is nonetheless likely to be underreported because of the lack of awareness of the disease, its non-specific clinical presentation, and lack of a rapid diagnostic test. Leptospirosis is endemic in most tropical countries and continues to occur sporadically in developed countries, especially in travellers who participate in water sports.

Leptospirosis should be considered in the differential diagnosis of any acute febrile illness. ${ }^{8}$ As there is an overlap of the clinical features of leptospirosis with other infections like influenza, dengue hemorrhagic fever, enteric fever and viral hepatitis A, a high index of suspicion is required to diagnose leptospirosis in a child, especially in endemic areas. Differential diagnoses in this 12-year-old girl included malaria, complicated enteric fever, dengue haemorrhagic fever. Severe acute respiratory syndrome was also considered because of prominent respiratory signs and symptoms. Although this is a multisystem disease with varying presentation, ${ }^{9}$ in our cases, prolonged fever, severe bleeding tendency, absence of hepatic and renal symptoms and signs were conspicuous.

Definitive diagnosis is based on demonstration of the infecting organism from clinical specimens of blood (first seven days), cerebrospinal fluid (day four to ten) and from urine (after tenth day) by phase contrast or dark field microscopy. However, the skill required and the high frequency of artifacts limits their use. ${ }^{8}$ Serologic tests like microscopic slide-agglutination test (MAT), indirect hemagglutination test, dipstick ELISA and dot ELISA for IgM antibodies, in the presence of clinical symptoms compatible with leptospires establish the diagnosis, ${ }^{8}$ as in our case. 
Table 1: laboratory findings

\begin{tabular}{|c|c|c|c|}
\hline $\begin{array}{l}\text { Laboratory } \\
\text { parameters }\end{array}$ & $\begin{array}{c}\text { Reference } \\
\text { range }\end{array}$ & $\begin{array}{c}\text { At the time of } \\
\text { admission to PICU }\end{array}$ & $\begin{array}{c}\text { At the time of } \\
\text { discharge from PICU }\end{array}$ \\
\hline Hemoglobin (g/L) & $132-167$. & 60 & 110 \\
\hline Total leucocyte count $\left(\mathrm{x} 10^{9} / \mathrm{L}\right)$ & $4.0-10.8$ & 19 & 7.2 \\
\hline Platelet count (x 109/L) & $140-380$ & 17 & 98 \\
\hline Urea (mmol/L) & $3.4-8.9$ & 8 & 5.8 \\
\hline Creatinine (micromol/L) & $44-80$ & 70 & 55 \\
\hline Total serum bilirubin(micromol/L) & $<15$ & 23 & 14 \\
\hline Alanine transaminase(IU/L) & $<58$ & 170 & 67 \\
\hline Alkaline phosphatase(IU/L) & $105-335$ & 670 & 287 \\
\hline Sodium (meq/L) & $120-145$ & 127 & 132 \\
\hline Potassium (meq/L) & $3.5-5.5$ & 4.9 & 4.2 \\
\hline Blood gas $\mathrm{pH}$ & $7.35-7.45$ & 7.20 & 7.39 \\
\hline $\mathrm{PCO} 2(\mathrm{kPa})$ & $4.7-6.0$ & 7.6 & 4.4 \\
\hline $\mathrm{PO} 2(\mathrm{kPa})$ & $10-13$ & 14 & 15 \\
\hline Base excess (mmol/L) & -2 to +2 & -8 & 0 \\
\hline
\end{tabular}

A 7- to 14-day course of penicillin $\mathrm{G}$ or amoxicillin is the recommended treatment for leptospirosis in children. ${ }^{10}$ In our patient, third-generation cephalosporin was initially prescribed, then changed to penicillin G. Avoidance of contact with and adequate disposal of urine from an infected patient is vital because Leptospira can still be detected in urine several months after the onset of the disease. ${ }^{11}$ In endemic areas, measures to prevent leptospirosis include strict rodent control and avoidance of contact with contaminated water and soil. When necessary, protective clothing, boots, and gloves should be worn and open wounds should be adequately covered.

\section{Conclusion}

Leptospirosis is not frequently reported in children and adolescents. A high index of suspicion is necessary to ensure prompt diagnosis. Patients condition can deteriorate rapidly if treatment is delayed. Leptospirosis should be considered in all febrile patients particularly with a suggestive history like exposure to freshwater, resident of endemic area or travel to such places, recent flood, rodents in the residing place, walking barefoot etc. 
A. Biswas et al. A case of leptospirosis in a child with unusual clinical manifestation

\section{Author's contributions}

$\mathrm{AB}$ was involved in drafting the manuscript and has made contributions to interpretation, performed the literature search, revision of the bibliography and helped with editing of the manuscript. AP has edited part of the manuscript and was involved in drafting the manuscript. RK \& AC were involved in drafting the manuscript and has made contributions to interpretation. All authors read, edited and approved the final manuscript.

\section{Acknowledgements}

We would like to thank Dr. Sunil Kr Hembram of the Department of Pediatric Medicine, Medical College \& Hospital, Kolkata, College Street, Kolkata-700041, India.

\section{References}

1. V.L. Andre, D. Diamen, R.T. Jaime. Leptospirosis in Latin America. Infect Dis Clin North Am 2000;14: 23-9.

2. S. Faines. Guidelines for control of leptospirosis. Geneva, World Health Organisation offset Publication 1982; 67.
3. T.J. John. Emerging and re-emerging bacterial pathogens in India. Indian J Med Res 1996;103:4-18.

4. Leptospirosis. India. Report of the investigation of a post-cyclone outbreak in Orissa. November, 1999. Wkly Epidemiol Rec 2000;75: 217-23.

5. R. Feigin, D. Anderson. Leptospirosis. In: Feigin R, Cherry J. editors. Textbook of Pediatric Inectious diseases, 3rd Edn. Philadelphia: W.B. Saunders; 1992;1167-83.

6. S. Gulati, S. Menon, M. Kabra et al Leptospirosis: A case report. Pediatr Today, 2002;7: 428-33.

7. S. Faine, B. Adler, C. Bolin. Leptospira and leptospirosis. $2^{\text {nd }}$ ed. Melborne, Australia: MediSci; 1999.

8. P. Azimi: Spirochetal Infections. In: W.E. Nelson, R.E. Behrman, R.M. Kliegman, et al, editors. Nelson Textbook of Pediatrics, 18th edn.vol:1, Philadelphia: W.B. Saunders Company; 2008;1271-73.

9. B. Verma, S.R. Daga, D. Sawant. leptospirosis in children. Indian Pediatrics 2003; 40:1081-3.

10. Leptospirosis. In: Pickering LK, editor. Red book: 2003 Report of the Committee on Infectious Diseases. 26th ed. Elk Grove Village, IL: American Academy of Pediatrics; 2003:403-5.

11. S. Rajajee, J. Shankar, L. Dhattatri. Pediatric presentations of leptospirosis. Indian J Pediatr 2002;69:851-3. 